\title{
Primary intra-abdominal malignant fibrous histiocytoma presenting as pyrexia of unknown origin - report of a case with review of literature
}

\author{
NA Qureshi*, MT Hallissey, JW Fielding and D Gourevitch
}

Address: Department of upper Gastro-intestinal surgery, Queen Elizabeth Hospital, Edgbaston, Birmingham, UK

Email: NA Qureshi* - surgeon_1@hotmail.com; MT Hallissey - mike.hallissey@uhb.nhs.uk; JW Fielding - john.fielding@uhb.nhs.uk;

D Gourevitch - david.gourevitch@uhb.nhs.uk

* Corresponding author

Published: 22 June 2006

International Seminars in Surgical Oncology 2006, 3:15 doi:10.1186/1477-7800-3-15

This article is available from: http://www.issoonline.com/content/3////5

(c) 2006 Qureshi et al; licensee BioMed Central Ltd.

This is an Open Access article distributed under the terms of the Creative Commons Attribution License (http://creativecommons.org/licenses/by/2.0), which permits unrestricted use, distribution, and reproduction in any medium, provided the original work is properly cited.
Received: 10 March 2006

Accepted: 22 June 2006

\begin{abstract}
Primary intra-abdominal malignant mesenchymal tumours are very rare and there are not many cases of visceral malignant fibrous histiocytoma in the English literature. We report a new case of abdominal malignant fibrous histiocytoma presenting as abdominal pain and pyrexia of unknown origin in a 54 year old female followed by a brief review of literature. Presentation with pyrexia of unknown origin is extremely rare in this condition.
\end{abstract}

\section{Background}

The term Malignant Fibrous Histiocytoma (MFH) was originally described by O'Brien and Stout in 1964 [1] to cover a variety of pleomorphic soft tissue sarcomas derived from histiocytes capable of fibroblastic transformation. MFH is a common sarcoma of mesenchymal origin affecting soft tissues of the body, especially the extremities and retroperitoneum. Primary intra-abdominal MFH is a rare disease and few cases are reported in the English literature. Its presentation as high-grade pyrexia of unknown origin (PUO) is extremely unusual. We report a case of malignant fibrous histiocytoma affecting colon, spleen, left hemi diaphragm and distal pancreas in a 54 year old female, who presented with abdominal pain and pyrexia of unknown origin.

\section{Case report}

A 54 year old female presented to our surgical outpatient clinic with abdominal pain and pyrexia. Abdominal pain was of recent onset and mainly in the left upper abdomen but she had fever for at least 6 months. Her pyrexia was high grade (39.5-40 $\left.\mathrm{C}^{0}\right)$, intermittent, and most common in the early morning. Clinical examination revealed a firm, vaguely defined, tender mass in the left upper quadrant of the abdomen. Blood results showed persistently high ESR (>100), high CRP ( $>240)$, leukocytosis, mildly raised Alkaline Phosphatase and anaemia (normochromic, normocytic). There was no overt source of infection that could account for the fever. Repeated blood cultures did not yield any bacterial growth. NM Leukocyte HMPAO scan showed no convincing abnormality to help localise an infective focus. There was no improvement in pyrexia after treating the patient with broad-spectrum antibiotics.

CT scan of the abdomen was performed which showed three heterogeneous masses in left upper abdomen relating to splenic flexure of colon, pancreatic body and tail and left crus of the diaphragm (figure 1). There was evidence of central necrosis in two of these masses. A trucut biopsy of the mass was performed and histology revealed spindle cell leiomyosarcoma. 


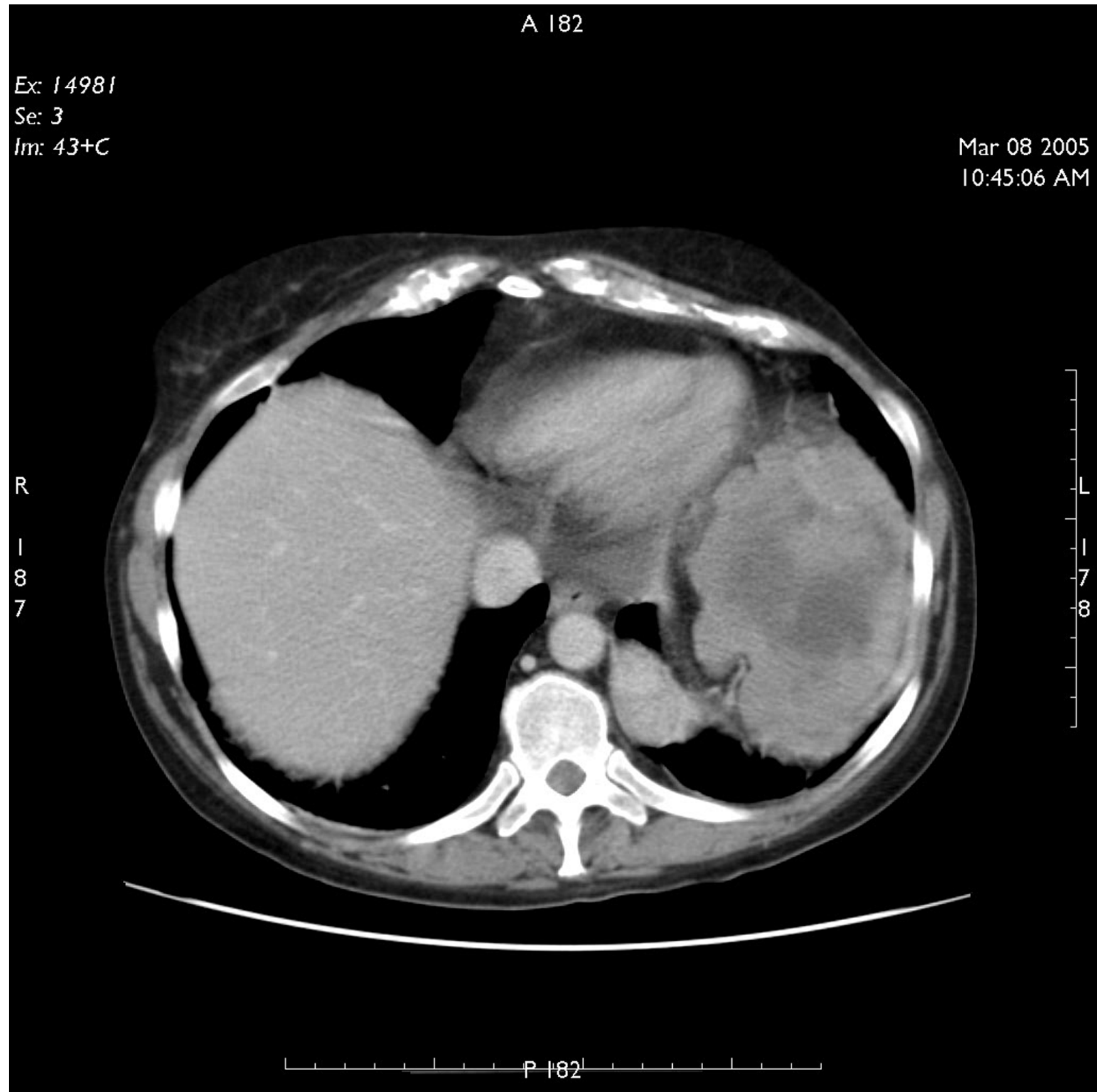

\section{Figure I}

CT scan of abdomen showing extent of primary tumour.

The patient was consented for surgery and distal pancreatectomy, splenectomy, left adrenalectomy and resection of part of colon was undertaken to remove the tumour via a left thoracoabdominal approach. The patient had an uneventful post-operative recovery and her pyrexia resolved completely following surgery.
Three different specimens were submitted for histology. Specimen A had a smooth external surface, measured 180 $\times 140 \times 130 \mathrm{~mm}$ and comprised of a multi-nodular mass with spleen and a loop of large bowel. The cut surface of the tumour was grey with large areas of necrosis up to $80 \%$. The bowel segment appeared to be entrapped and focally infiltrated by the tumour up to the mucosa; how- 
ever, both cut ends margins were free of tumour. Specimen $\mathrm{B}$ comprised of lobulated mass with fatty tissue and measured $140 \times 60 \times 30 \mathrm{~mm}$. Some adrenal tissue was identified which was not involved by the tumour. Specimen C consisted of four pieces of haemorrhagic tissue.

Microscopically, specimen A showed a mixture of patterns; in some areas, spindle cells with hyalinisation and in other, pleomorphic cells mixed tumour and osteoclast giant cells. Focally, tumour cells had long thin cytoplasmic processes and wavy nuclei. In addition, there was a prominent inflammatory cell infiltrate in the background with foamy histiocytes. Also, the nuclear atypia was marked with a brisk mitotic activity. Immunohistochemistry of the tumour showed smooth muscle actin (SMA) to be focally positive, but Desmin, CD34, S-100, Neurofila- ment, EMA, CAM 5.2, CD117, CD21 and CD23 were negative. All these appearances were suggestive of a highgrade sarcoma with no discernible line of differentiation; hence it was best classified as grade 3 malignant fibrous histiocytoma. Specimen B showed spindle cell sarcoma with cells showing elongated thin cytoplasmic processes and wavy nuclei. Specimen C showed spindle-pleomorphic sarcoma (Figure 2).

Two months following resection of the tumour, the patient again developed high-grade fever. This was associated with left shoulder pain and weight loss. Investigations showed anaemia and hypercalcaemia. On CT scanning, she was found to have local recurrence of the tumour (figure 3 ) as well as liver metastases (figure 4). At

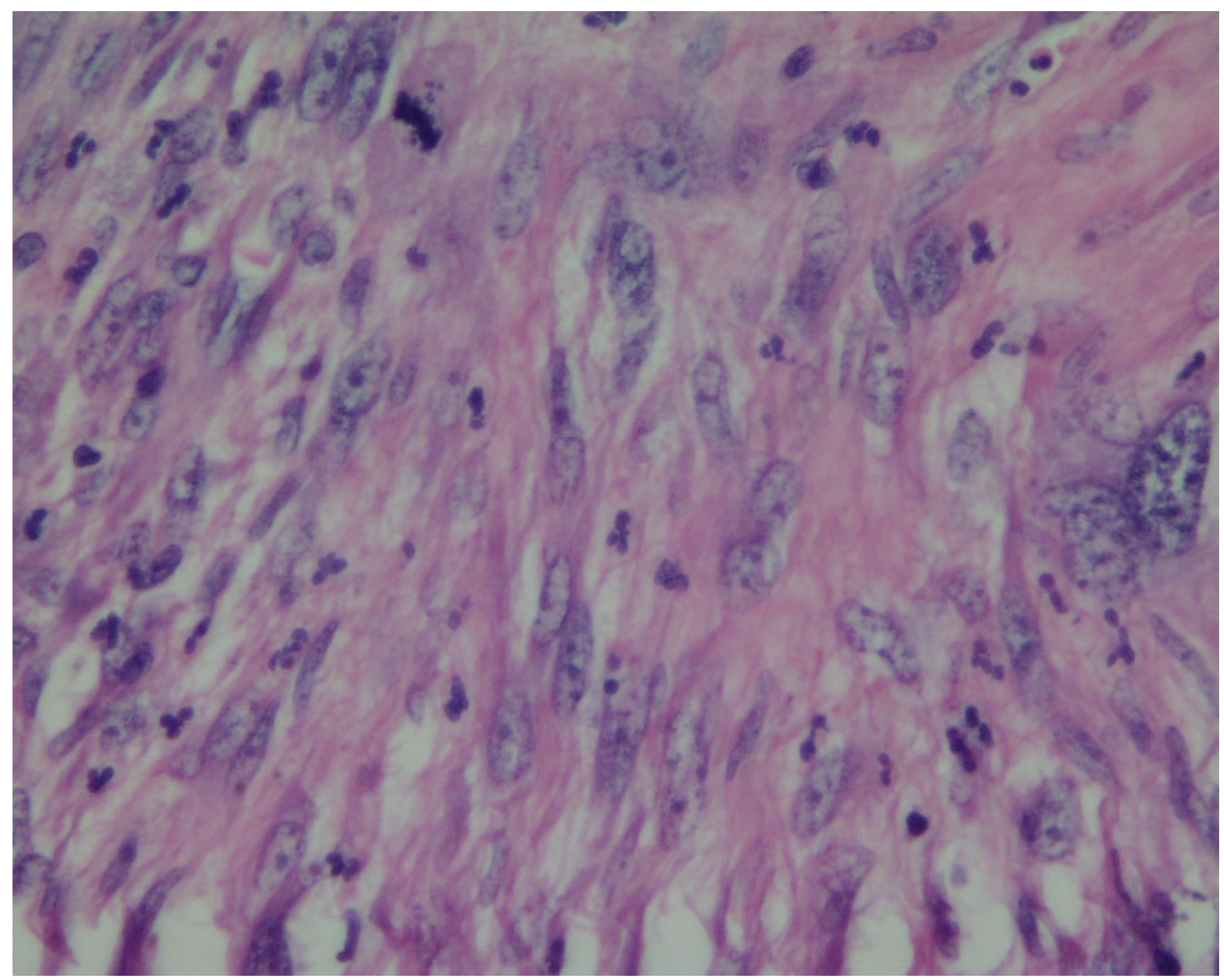

Figure 2

Histopathology image showing spindle to pleomorphic sarcoma with nuclear atypia and mitotic activity. 


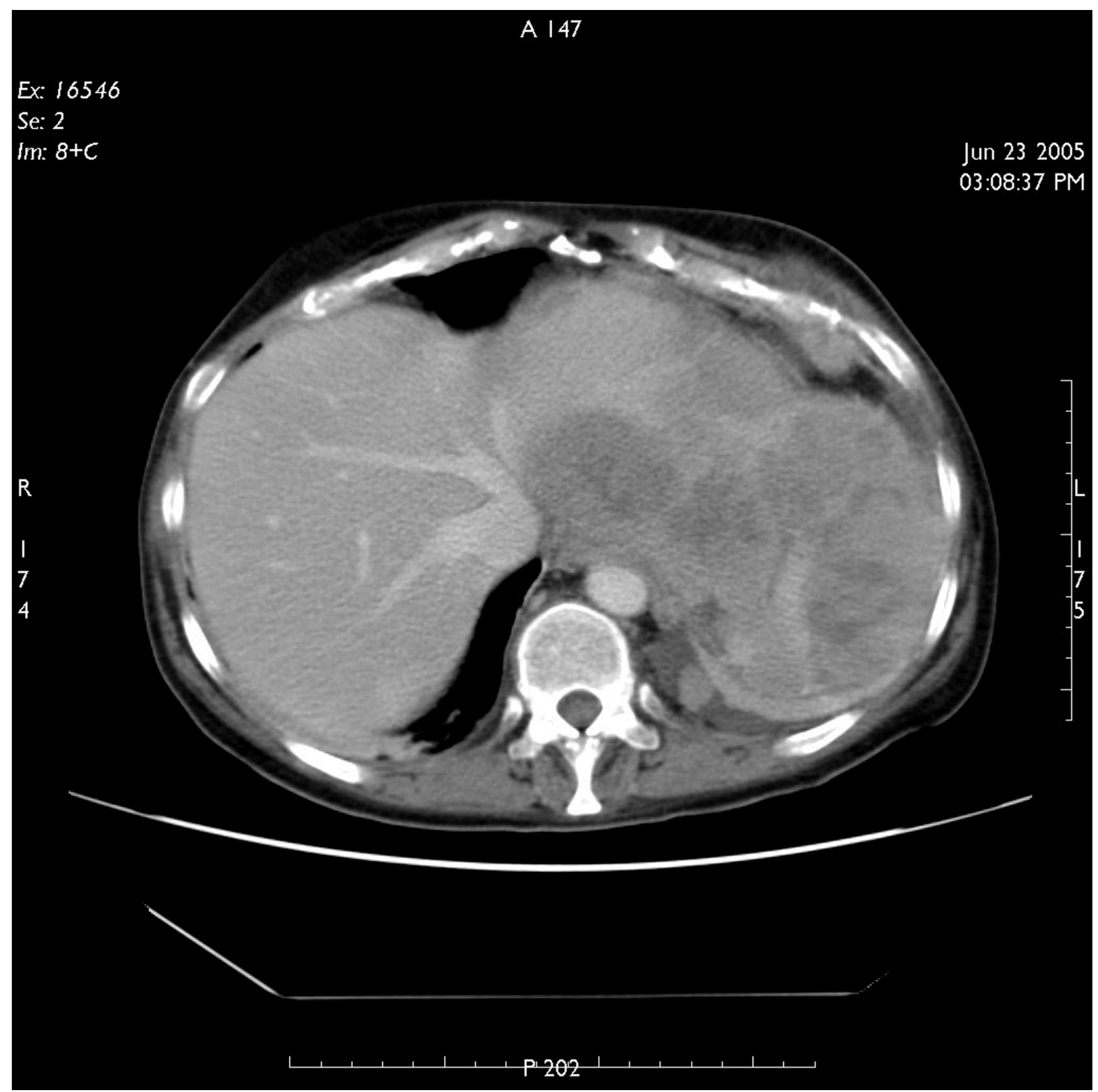

\section{Figure 3}

$\mathrm{CT}$ scan of abdomen showing local recurrence of the tumour.

this stage, patient was referred to the oncology department but unfortunately died 8 weeks later.

\section{Discussion}

Malignant Fibrous Histiocytoma is a sarcoma of mesenchymal origin affecting soft tissues of the body, particularly the extremities and retroperitoneum. Rarely, it may affect intra-peritoneal organs. Its occurrence has been reported in almost all parts of the body including head and neck [2], intracranial [3,4], intra-abdominal organs $[5,6]$ and heart muscle [7]. It is considered as the most common soft tissue sarcoma of the adults [8], but may occur in children as well as infants [9].

The mode of presentation of MFH depends on the primary site of the body affected by the tumour, for example, 


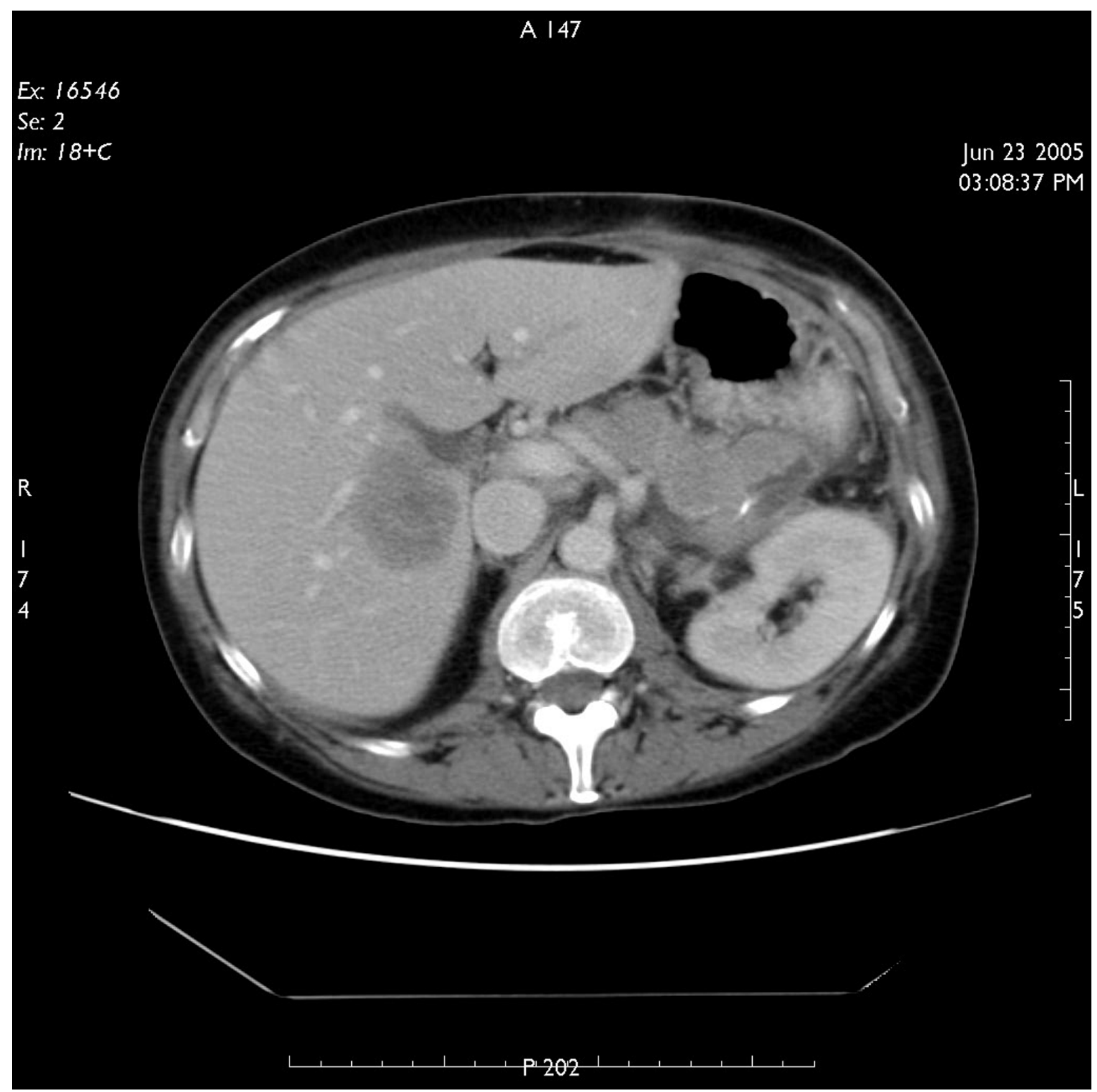

\section{Figure 4}

CT scan of abdomen showing liver metastases.

dyspnoea and arrhythmias can be caused by cardiac lesions. In addition, symptoms of systemic illness caused by the tumour may also be the presenting complaint. Reporting our patient, intra-abdominal MFH presented as pyrexia of unknown origin, caused likely by tumour necrosis and release of inflammatory and pyrogenic factors.
On the basis of its wide range of histological appearances, Enzinger and Weiss subdivided MFH into five sub-types $[10,11]$ :

1. Storiform-pleomorphic

2. myxoid (myxofibrosarcoma) 
3. Giant cell (malignant giant cell tumor of soft parts and has the worst prognosis)

4. Inflammatory (xanthosarcoma and malignant xanthogranuloma)

\section{Angiomatoid.}

Investigations for the diagnosis of MFH include routine haematological, biochemical and radiological tests. A CT scan of the abdomen should be performed early in a patient who presents with abdominal pain and pyrexia of unknown origin but no obvious source of symptoms. This can help identify and localise tumours, if and define extent of growth and presence of metastatic disease. The final diagnosis of MFH is based primarily on the histopathological examination and immunohistochemical reactivity. These diagnostic procedures rely on several criteria, which include the presence of typical spindle and polygonal (strap-like) cells that are filled with an abundant eosinophilic cytoplasm, cells with cross-striations, and, particularly, desmin- and myoglobin-positive immunoreactivity $[12,13]$. However, the presence of cytoplasmic filaments is not always found in MFH and makes it harder to establish a reliable differential diagnosis.

MFH is an aggressive tumour with a high potential of metastasis to other parts of the body. The Liver is the most commonly involved site of metastatic sarcomas, occurring in $64 \%-70 \%$ of patients $[15,16]$. The current treatment of choice for primary malignant fibrous histiocytomas is surgical resection $[14,15]$, which involves wide excision of the tumour with an aim for tumour free margins. Recurrence of the tumour is not uncommon even when resection margins are tumour free. Metastasis may present months or years after resection of the primary lesion. Treatment for metastatic disease is surgical where possible; palliative surgery may be carried out if complete resection is not possible. The role of adjuvant radiotherapy and chemotherapy is not clear in the case of retroperitoneal and visceral sarcomas. There are studies that suggest no improvement in overall survival after systemic chemotherapy [16-18]. Some advocate the use of chemoembolization for unresectable metastatic sarcomas, which can provide durable tumour response [19].

\section{Conclusion}

In order to improve survival in patients with MFH, complete resection of the primary tumour as well as isolated peritoneal or hepatic metastases should be attempted where possible. An early multidisciplinary approach is important to improve clinical outcome. Our case report shows that primary intra-abdominal MFH can present in unusual ways including high-grade fever of unknown origin. Clinicians must remember this while establishing dif- ferential diagnosis for patients with PUO and abdominal pain.

\section{Competing interests}

The author(s) declare that they have no competing interests.

\section{Acknowledgements}

Many thanks to Dr Deshmukh for providing histopatholgy image.

Written consent was obtained from patient's next of kin.

\section{References}

I. O'Brien JE, Stout AP: Malignant fibrous xanthomas. Cancer 1964, I 7:| 445-55.

2. Sadati KS, Haber M, Sataloff RT: Malignant fibrous histiocytoma of the head and neck after radiation for squamous cell carcinoma. Ear Nose Throat J 2004, 83(4):280-I.

3. Ozhan S, Tali ET, Isik S, Saygili MR, Baykaner K: Haematoma-like primary intracranial malignant fibrous histiocytoma in a 5 year-old girl. Neuroradiology I999, 4 I(7):523-5.

4. Fujimoura N, Sugita $Y$, Hirohata $M$, Naohisa $M$, Terasaki $M$, Tokutmi T, Shigemori M: Primary Intracerebral Malignant Fibrous Histiocytoma in a Child. Paediatric Neurosurgery Basel 2002, 37(5):27I-5.

5. Kotan C, Kosem M, Alici S, Ilhan M, Tuncer I, Harman M: Primary malignant fibrous histiocytoma of the small intestine presenting as an intussusception: report of a case. Surg Today 2002, 32(I 2): 109|-5

6. Gruttadauria S, Doria C, Minervini MI, Doyle HR, Mandala L, Foglieni $\mathrm{CS}$, et al.: Malignant fibrous histiocytoma of the gallbladder: case report and review of the literature. Am Surg 200I, 67(7):7|4-7.

7. Donsbeck AV, Ranchere D, Coindre JM, Le Gall F, Cordier JF, Loire R: Primary cardiac sarcomas: an immunohistochemical and grading study with long-term follow-up of $\mathbf{2 4}$ cases. Histopathology 1999, 34(4):295-304.

8. Singh B, Shaha A, Har-El G: Malignant fibrous histiocytoma of the head and neck. J Craniomaxillofac Surg 1993, 2 1:262-5.

9. $\mathrm{Kim} \mathrm{OH}$, Lee KY: Malignant fibrous histiocytoma of primary omental origin in an infant. Pediatr Radiol 1994, 24(4):285-7.

10. Enzinger F: Recent developments in the classification of soft tissue sarcomas. In Management of Primary Bone and Soft Tissue Sarcomas Chicago: Year Book of Medical Publishers, Inc; 1977.

II. Enzinger FM, Weiss SW: Soft Tissue Tumors. St. Louis: CV Mosby; 1983:166-198.

12. Miettinen $M$ : Rhabdomyosarcoma in patients older than $\mathbf{4 0}$ years of age. Cancer 1988, 62:2060-2065.

13. De Jong ASH, Van Kessel-Van Mark M, Albus Lutter CE: Pleomorphic rhabdomyosarcoma in adults: immunohistochemistry as a tool for its diagnosis. Hum Pathol 1987, I 8:298-303.

14. Ng EH, Pollack RE, Romsdahl M: Prognostic implications of patterns of failure for gastrointestinal leiomyo- sarcomas. Cancer 1992, 69:|334-|34|.

15. Lee YTN: Leiomyosarcomas of the gastrointestinal tract: general pattern of metastasis and recurrence. Cancer Treat Rev 1984, 10:91-101.

16. Edmonson JH, Ryan LM, Blum RH, Brooks JS, Shiraki M, Frytak S, et al.: Randomized comparison of doxorubicin alone versus ifosfamide plus doxorubicin or mitomycin, doxorubicin and cisplatin against advanced soft tissue sarcomas. J Clin Oncol 1993, I I:1269-1275.

17. Casper ES, Christman KL, Schwartz GK, Johnson B, Brennan MF, Bertino JR: Edatrexate in patients with soft tissue sarcoma. Cancer 1993, 72:766-770.

18. Wilson RE, Wood WC, Lerner HL, Antman K, Amato D, Corson JM, et al: Doxorubicin chemotherapy in the treatment of soft-tissue sarcoma - combined results of two randomized trials. Arch Surg 1986, I2 1:1354-1359.

19. Rajan DK, Soulen MC, Clark TW, Baum RA, Haskal Z], ShlanskyGoldberg RD, et al:: Sarcomas metastatic to the Liver: Response and Survival after Cisplatin, Doxorubicin, Mitomy- 
cin-C, Ethiodol, and Polyvinyl Alcohol Chemoembolization Journal of Vascular and Interventional Radiology. 200I, 12:187-193.

Publish with Bio Med Central and every scientist can read your work free of charge

"BioMed Central will be the most significant development for disseminating the results of biomedical research in our lifetime. " Sir Paul Nurse, Cancer Research UK

Your research papers will be:

- available free of charge to the entire biomedical community

- peer reviewed and published immediately upon acceptance

- cited in PubMed and archived on PubMed Central

- yours - you keep the copyright 